\title{
Cost Effectiveness of New Oral Anticoagulants for Stroke Prevention in Patients with Atrial Fibrillation in Two Different European Healthcare Settings
}

\author{
Talitha I. Verhoef • William K. Redekop • \\ Fazila Hasrat • Anthonius de Boer • \\ Anke Hilse Maitland-van der Zee
}

Published online: 18 October 2014

(c) The Author(s) 2014. This article is published with open access at Springerlink.com

\begin{abstract}
Objectives Our objectives were to investigate the cost effectiveness of apixaban, rivaroxaban, and dabigatran compared with coumarin derivatives for stroke prevention in patients with atrial fibrillation in a country with specialized anticoagulation clinics (the Netherlands) and in a country without these clinics (the UK).

Methods A decision-analytic Markov model was used to analyse the cost effectiveness of apixaban, rivaroxaban, and dabigatran compared with coumarin derivatives in the Netherlands and the UK over a lifetime horizon.

Results In the Netherlands, the use of rivaroxaban, apixaban, or dabigatran increased health by $0.166,0.365$, and 0.374 quality-adjusted life-years (QALYs) compared with coumarin derivatives, but also increased costs by $€ 5,681, € 4,754$, and $€ 5,465$, respectively. The incremental cost-effectiveness ratios (ICERs) were $€ 34,248$, $€ 13,024$, and $€ 14,626$ per QALY gained. In the UK, health was increased by $0.302,0.455$, and
\end{abstract}

Electronic supplementary material The online version of this article (doi:10.1007/s40256-014-0092-1) contains supplementary material, which is available to authorized users.

T. I. Verhoef · F. Hasrat · A. de Boer · A. H. Maitland-van der Zee Division of Pharmacoepidemiology and Clinical Pharmacology, Faculty of Science, Utrecht Institute of Pharmaceutical Sciences, Utrecht University, P. O. Box 80 082, 3508 TB Utrecht,

The Netherlands

A. H. Maitland-van der Zee

e-mail: a.h.maitland@uu.nl

T. I. Verhoef $(\bowtie)$

Department of Applied Health Research, University College

London, London, UK

e-mail: t.verhoef@ucl.ac.uk

W. K. Redekop

Institute for Medical Technology Assessment, Erasmus

University, Rotterdam, The Netherlands
0.461 QALYs, and the incremental costs were similar for all three new oral anticoagulants $(€ 5,118-5,217)$. The ICERs varied from $€ 11,172$ to 16,949 per QALY gained. In the Netherlands, apixaban had the highest chance (37\%) of being cost effective at a threshold of $€ 20,000$; in the UK, this chance was $41 \%$ for dabigatran. The quality of care, reflected in time in therapeutic range, had an important influence on the ICER. Conclusions Apixaban, rivaroxaban, and dabigatran are cost-effective alternatives to coumarin derivatives in the UK, while in the Netherlands, only apixaban and dabigatran could be considered cost effective. The cost effectiveness of the new oral anticoagulants is largely dependent on the setting and quality of local anticoagulant care facilities.

\section{Key Points}

New oral anticoagulants such as apixaban, rivaroxaban, and dabigatran likely result in higher quality-adjusted life-years (QALY) if compared with coumarin anticoagulants in the Netherlands and the UK, but at increased treatment costs.

Compared with coumarin derivatives, all new oral anticoagulants could be considered cost effective in both the Netherlands and the UK, except rivaroxaban in the Netherlands.

In the Netherlands, apixaban had the highest chance of being cost effective at a willingness-to-pay threshold of $€ 20,000$ per QALY gained; in the UK, dabigatran had the highest chance of being cost effective at this threshold.

The cost effectiveness of new oral anticoagulants is largely dependent on the setting and quality of local anticoagulant care facilities. 


\section{Introduction}

Patients with atrial fibrillation (AF) are at increased risk of stroke and other thromboembolic events. Therefore, an anticoagulant is often indicated to decrease this risk [1]. Vitamin K antagonists (or coumarin derivatives) have been used for many years as oral anticoagulants for stroke and systemic embolism (SE) prevention in patients with AF. These drugs have a small therapeutic window and a large inter-individual and intra-individual variability in dose response. Frequent monitoring of the anticoagulant effect (expressed as international normalised ratio [INR]) is therefore required [2]. Recently, new oral anticoagulants have become available for the prevention of stroke and SE in patients with $\mathrm{AF}$. These drugs do not require such monitoring and have been shown in randomized controlled trials to be non-inferior or even superior to warfarin in the prevention of stroke and SE [3-6].

Dabigatran is a direct thrombin inhibitor and, at a dose of $150 \mathrm{mg}$, this anticoagulant is associated with a lower rate of stroke and SE and a similar bleeding rate if compared with warfarin [3,4]. An increased risk of myocardial infarction (MI) was seen in dabigatran users [3], although this difference was not statistically significant in a re-analysis after identification of additional events [4]. Apixaban is a factor Xa inhibitor and was shown to decrease the risk of stroke and SE as well as the risk of bleeding [5]. Another factor Xa inhibitor, rivaroxaban, was non-inferior to warfarin for the prevention of stroke and SE, and fewer intracranial or fatal bleeding events occurred in patients using this drug [6]. The risk of gastrointestinal bleeding was increased in rivaroxaban users and in dabigatran users [7, 8]. All three new oral anticoagulant drugs are considered useful alternatives to warfarin [7]. However, since the costs of these new drugs are considerably higher than the costs of coumarins, it is important to investigate their cost effectiveness carefully.

The cost effectiveness of dabigatran, apixaban, and rivaroxaban has been investigated in several studies, and all three were shown to be cost effective when systematically reviewed $[9,10]$. When the quality of the warfarin treatment is higher (a higher percentage of time is spent in the therapeutic INR range), the chance that dabigatran is cost effective is lower. Because the quality of the treatment with coumarin derivatives varies across different countries and different healthcare settings, the cost effectiveness of the new oral anticoagulants needs to be investigated in different settings [11]. In the Netherlands, treatment with coumarin derivatives is monitored and guided by specialised anticoagulation clinics. The percentage time patients spent in the therapeutic INR range in this country is $76-79 \%$ for patients using short- or long-term (2 months to lifetime) acenocoumarol, which is the most frequently used coumarin (approximately $80 \%$ of the cases; phenprocoumon is used in the remaining cases) in the Netherlands [12]. In the UK, warfarin is most frequently used, and most of the warfarin users are treated by general practitioners [13]. The percentage time spent in the therapeutic INR range is lower than in the Netherlands; one estimate was approximately $63 \%$ [14]. The aim of this study is therefore to investigate the cost effectiveness of apixaban, rivaroxaban, and dabigatran compared with coumarin derivatives in a country with specialized anticoagulation clinics (the Netherlands) and in a country without these clinics (the UK).

\section{Methods}

\subsection{Model Structure}

A decision-analytic Markov model was used to analyse the cost effectiveness of the three new oral anticoagulants (apixaban, rivaroxaban, and dabigatran) compared with coumarin derivatives. The model was developed using TreeAge software (TreeAge Pro 2012) and Microsoft Excel. The base-case analysis consisted of a hypothetical cohort of patients with $\mathrm{AF}$, aged 70 years, initiating oral anticoagulant therapy.

Figure 1 shows the decision tree with the four treatment options. The decision-analytic Markov model consisted of nine health states: healthy with $\mathrm{AF}$, ischaemic stroke (IS), transient ischaemic attack (TIA), MI, SE, intracranial hemorrhage $(\mathrm{ICH})$, extracranial hemorrhage $(\mathrm{ECH})$, disability, and death. All patients entered the model in the 'healthy with AF' state and could move to one of the other states at monthly intervals. Patients with an IS had a $37 \%$ chance of dying and $32 \%$ chance of disability $[5,6]$. The chance that an ICH would be disabling was $50 \%$, and that it would be fatal was $44 \%[12,16]$. MI and ECH were fatal in 16 and $7 \%$ of the cases, respectively [12, 17, 18]. We assumed a similar percentage of fatal cases (7 \%) in SE as in ECH and a mortality rate of $5.6 \%$ in patients in the disability state [19]. Age-specific mortality rates were taken into account for all patients using UK- and the Netherlands-specific life tables [20, 21], excluding cerebrovascular deaths [22] (see Table S1 in the electronic supplementary material $[\mathrm{ESM}])$. Input parameters of the model for both the Netherlands and the UK are shown in Table 1.

\subsection{Clinical Event Rates}

Annual rates of clinical events of the new oral anticoagulants were derived from three large randomized controlled 
trials, because these trials provide the most reliable and exhaustive data on events with new oral anticoagulants currently available. Data from the ARISTOTLE trial were used for event rates of apixaban at a dose of $5 \mathrm{mg}$ twice daily [5], data from the ROCKET-AF trial for rivaroxaban $20 \mathrm{mg}$ once daily [6], and from the RE-LY trial for dabigatran $150 \mathrm{mg}$ twice daily [3, 4]. The indirect comparison method by Bucher et al. [23] was used to adjust for differences in baseline risks between the three trials. Hazard ratios and their $95 \%$ confidence intervals for clinical events with rivaroxaban and dabigatran versus apixaban were calculated and used to provide adjusted baseline risks for rivaroxaban and dabigatran. More detail on this method and the hazard ratios used are provided in Table $\mathrm{S} 2$ in the ESM.

To correct for differences in quality of coumarin anticoagulant care, the rates of clinical events of coumarin derivatives were not taken from the clinical trials mentioned above, but based on the time spent in the therapeutic INR range. The risks of thromboembolic and hemorrhagic events associated with different INR ranges were derived from a meta-analysis by Oake et al. [24]. In this meta-analysis, the risk of events was calculated based on 19 studies, including randomized trials as well as observational studies on warfarin, acenocoumarol, or phenprocoumon. The proportion of thromboembolic events that were stroke, MI, or SE and the proportion of hemorrhagic events that were intracranial or extracranial were derived from the warfarin arms of the three trials of the new oral anticoagulants (weighted average) [3-6]. As in previous cost-effectiveness studies, we assumed that $28 \%$ of ischemic strokes were TIA $[25,26]$. More detail on the calculation of event rates for coumarin derivatives is provided in Tables S3 and S4 in the ESM. In our model, we used a percentage time spent in the target range of $76 \%$ for the Netherlands and $63 \%$ for the UK after the initiation

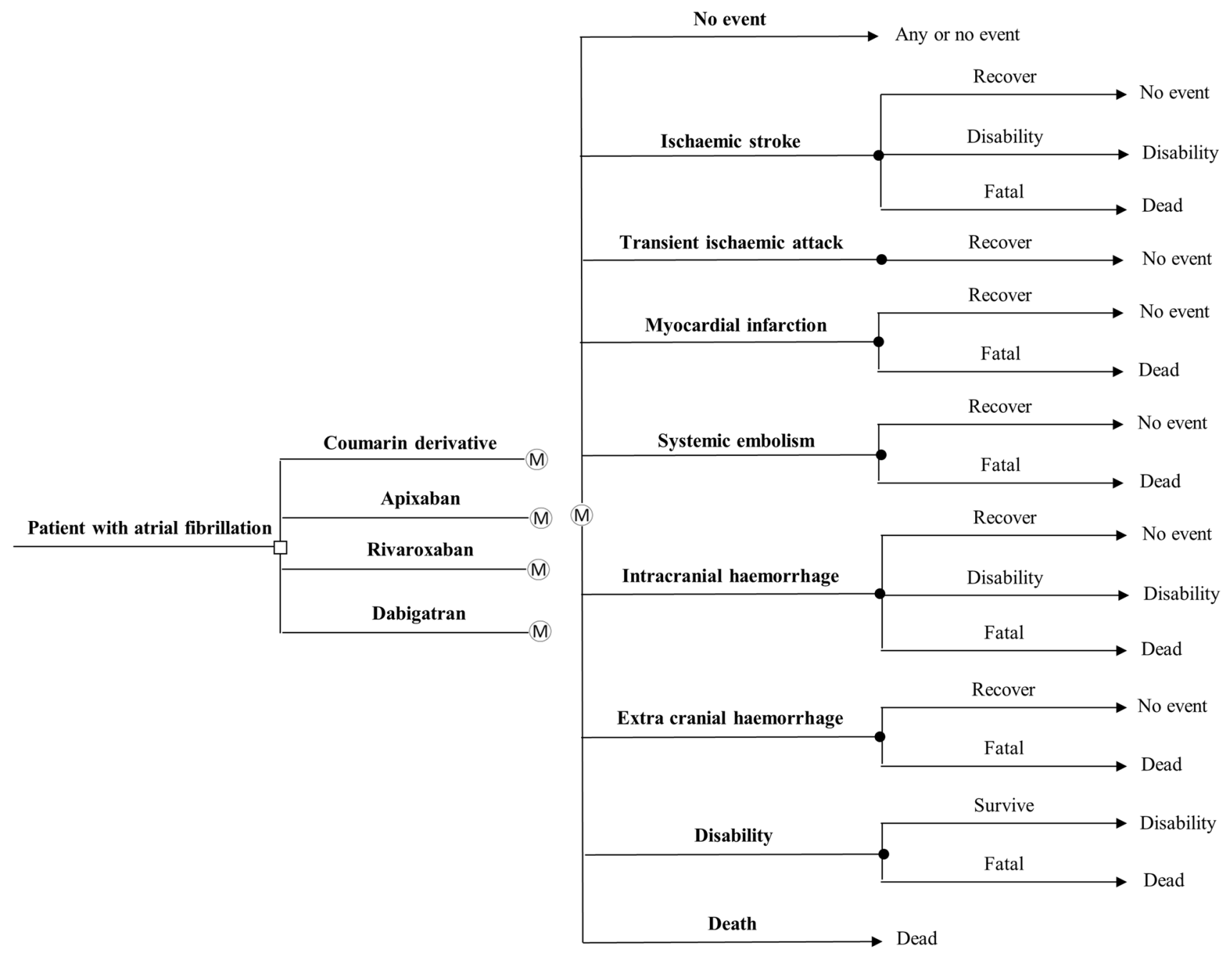

Fig. 1 Schematic representation of the decision tree and Markov model. Patients initiating oral anticoagulant therapy can be treated by one of the four drugs with different chances of developing adverse events 
Table 1 Model input parameters for both the Netherlands and the UK

\begin{tabular}{|c|c|c|c|c|}
\hline Parameter & Base case & Range & Source & Distribution \\
\hline Age at start of treatment & 70 & $60-80^{\mathrm{a}}$ & a & Normal \\
\hline \multicolumn{5}{|l|}{ Outcome of events (if occurring) \% } \\
\hline Fatal stroke & 37 & $33-41^{\mathrm{c}}$ & {$[5,6]$} & Dirichlet \\
\hline Disabling stroke & 32 & $28-36^{\mathrm{c}}$ & {$[5,6]$} & Dirichlet \\
\hline Fatal transient ischemic attack & 0 & - & a & - \\
\hline Fatal systemic embolism & 7 & $5.6-8.4^{\mathrm{b}}$ & a & Beta \\
\hline Fatal myocardial infarction & 16 & $13-19^{\mathrm{b}}$ & {$[17,18]$} & Beta \\
\hline Fatal intracranial hemorrhage & 44 & $40-48^{\mathrm{c}}$ & {$[12]$} & Dirichlet \\
\hline Disabling intracranial hemorrhage & 50 & $46-54^{\mathrm{c}}$ & [16] & Dirichlet \\
\hline Fatal extracranial hemorrhage & 7 & $5.6-8.4^{\mathrm{b}}$ & [12] & Beta \\
\hline Monthly mortality rate disability state & 5.6 & $4.5-6.7^{\mathrm{b}}$ & [19] & Beta \\
\hline \multicolumn{5}{|l|}{ QALYs and decrements } \\
\hline Atrial fibrillation & 0.81 & 0.67819 to $0.91373^{\mathrm{c}}$ & {$[28]$} & Beta \\
\hline Use of coumarin derivative & -0.013 & -0.002 to $-0.033^{\mathrm{c}}$ & {$[28]$} & Beta \\
\hline Use of new oral anticoagulant & -0.006 & -0.004 to $-0.007^{\mathrm{c}}$ & {$[25]$} & Beta \\
\hline Use of aspirin & -0.002 & 0.000 to $-0.006^{\mathrm{c}}$ & {$[25]$} & Beta \\
\hline Stroke & -0.1385 & -0.11843 to $-0.15998^{c}$ & {$[28]$} & Beta \\
\hline Transient ischemic attack & -0.10322 & -0.09912 to $-0.11894^{\mathrm{c}}$ & {$[28]$} & Beta \\
\hline Systemic embolism & -0.1199 & -0.10224 to $-0.13880^{\mathrm{c}}$ & {$[28]$} & Beta \\
\hline Myocardial infarction & -0.1247 & -0.10645 to $-0.14356^{\mathrm{c}}$ & {$[28]$} & Beta \\
\hline Intracranial hemorrhage & -0.1814 & -0.15500 to $-0.20885^{\mathrm{c}}$ & [28] & Beta \\
\hline Extracranial hemorrhage & -0.06 & -0.02 to $-0.10^{\mathrm{c}}$ & [19] & Beta \\
\hline Disability & -0.374 & -0.160 to $-0.588^{\mathrm{c}}$ & [19] & Beta \\
\hline
\end{tabular}

a Assumption

b $\pm 20 \%$

c $95 \%$ Confidence interval

$Q A L Y$ quality-adjusted life-year

period ( 2 months) $[12,14]$. In the first month of treatment, this percentage was $50 \%$ (unpublished data [27]). During the first 2 months, $75 \%$ of the out-of-range INRs were sub-therapeutic (INR <2) and, after the initiation period, out-of-range INRs were more often supra-therapeutic (70 \% INR >3) (unpublished data [27]). The percentages of time spent in the different INR ranges were then multiplied by the risk of events associated with these ranges [24] to calculate the incidence of thromboembolic and hemorrhagic events in every cycle. Patients using coumarin anticoagulants did not undergo pharmacogenetic testing. Patients receiving either one of the new oral anticoagulants or coumarin therapy were assumed to switch to aspirin after an ICH [1]. The annual rates of clinical events of the different treatment options are shown in Table S3 of the ESM.

\subsection{Quality of Life and Costs}

The baseline quality of life in our model was 0.81 for patients with AF [28]. A decrement of 0.013 was applied for coumarin use and a decrement of 0.006 for apixaban, rivaroxaban, or dabigatran use. Decrements were also ascribed when patients experienced an adverse event. Table 1 shows quality-adjusted life-year (QALY) values and decrements for the different health states.

The frequency of INR measurements varied from 15.7 to 25.4 per year, with a median of 21.4 in Dutch anticoagulant clinics [12], and has been estimated to be in the range of 8-12 per year (we assumed an average of ten per year) in the UK [29]. The frequency of measurements in the Netherlands is higher, probably because a care system with many anticoagulant clinics exists in this country, so that patients can be seen frequently in a clinic close to their home, while in the UK it is not feasible for patients travel to the hospital that often. Also, in the UK, each hospital has its own protocol for the monitoring patients, while in the Netherlands, all anticoagulant clinics work according to the same protocol. We assumed four extra measurements in the first month and one extra measurement after an adverse event. Costs of an INR measurement were derived from the Dutch healthcare authority tariff and from a report of the 
National Institute for Health and Care Excellence (NICE) [30, 31]. Monthly drug costs were estimated using data from the Dutch healthcare insurance board and the NICE report $[31,32]$. Costs of the drugs and adverse events are shown in Table 2. The data on costs were derived from different sources. There can be differences according to perspective, year of analysis, and the items included in the calculations of overall costs. We tried to find the best available data for both countries and varied these in the sensitivity analysis. Costs were determined from a healthcare sector perspective for the year 2012 in Euros $(€)$. While the Dutch guidelines recommend using a societal perspective, we used a healthcare sector perspective since most of the cost differences were expected to be found in this sector.

Effects were discounted at an annual rate of $1.5 \%$ for the Netherlands and $3.5 \%$ for the UK, and costs at an annual rate of 4 and $3.5 \%$, respectively, in accordance with national guidelines [33, 34]. Because of the different guidelines regarding discount rates in the two countries, we also performed the analysis without discounting.

\subsection{Base-Case and Sensitivity Analyses}

Total costs and QALYs of each treatment strategy (apixaban, rivaroxaban, dabigatran, and the coumarin derivative) as well as the incremental cost-effectiveness ratios (ICERs) were calculated based on means from the simulations in the probabilistic sensitivity analysis (see below). Several sensitivity analyses were also performed. First, one-way sensitivity analyses were conducted to examine the impact of key model parameters and assumptions on the results. The parameters were varied over their $95 \%$ confidence intervals or decreased and increased by $20 \%$ if a confidence interval was not available (see Tables 1,2 and Table S3 in the ESM). The costs of events were varied over

Table 2 Country-specific model input parameters

\begin{tabular}{|c|c|c|c|c|c|c|}
\hline \multirow[t]{2}{*}{ Parameter } & \multicolumn{3}{|c|}{ The Netherlands } & \multicolumn{2}{|l|}{ UK } & \multirow[t]{2}{*}{ Distribution } \\
\hline & Base c & ge) & Source & Base case (range) & Source & \\
\hline \multicolumn{7}{|c|}{ Time in therapeutic range $(\%)$} \\
\hline Month 1 a & & $50\left(40-60^{\mathrm{a}}\right)$ & $\mathrm{b}$ & $50\left(40-60^{a}\right)$ & $\mathrm{b}$ & Normal \\
\hline Month 3 a & & $76\left(63-89^{a}\right)$ & $\mathrm{b}$ & $63\left(50-76^{\mathrm{a}}\right)$ & [14] & Normal \\
\hline \multicolumn{7}{|c|}{ Number of INR measurements (monthly) } \\
\hline Maintenan & & $1.8\left(1.3-2.1^{\mathrm{c}}\right)$ & {$[12]$} & $0.83\left(0.67-1^{\mathrm{a}}\right)$ & [29] & Normal \\
\hline Extra duri & & $4\left(2-6^{\mathrm{a}}\right)$ & a & $4\left(2-6^{\mathrm{a}}\right)$ & a & Normal \\
\hline \multicolumn{7}{|l|}{ Costs $(€)$} \\
\hline Coumarin & & $1.50\left(1.20-1.80^{\mathrm{d}}\right)$ & {$[32]$} & $4.47\left(3.58-5.37^{\mathrm{d}}\right)$ & {$[31]$} & Gamma \\
\hline Apixaban & & $68\left(55-82^{d}\right)$ & {$[32]$} & $82\left(66-98^{\mathrm{d}}\right)$ & {$[31]$} & Gamma \\
\hline Rivaroxab & & $64\left(51-77^{\mathrm{d}}\right)$ & {$[32]$} & $78\left(63-94^{\mathrm{d}}\right)$ & [31] & Gamma \\
\hline Dabigatrai & & $68\left(55-82^{\mathrm{d}}\right)$ & {$[32]$} & $82\left(66-98^{\mathrm{d}}\right)$ & [31] & Gamma \\
\hline Aspirin (n & & $2.83\left(2.26-3.40^{\mathrm{d}}\right)$ & {$[32]$} & $3.36\left(2.68-4.03^{\mathrm{d}}\right)$ & {$[35]$} & Gamma \\
\hline INR meas & r visit) & $10.38\left(8.30-12.46^{\mathrm{d}}\right)$ & {$[30]$} & $30.40\left(24-36^{\mathrm{d}}\right)$ & {$[31]$} & Gamma \\
\hline Stroke & & $19,652\left(14,000-24,000^{\mathrm{a}}\right)$ & [36] & $14,750\left(10,000-20,000^{\mathrm{a}}\right)$ & [37] & Gamma \\
\hline Transient & $\mathrm{ck}$ & $949\left(750-1,150^{\mathrm{a}}\right)$ & [38] & $1,115\left(850-1,350^{\mathrm{a}}\right)$ & [39] & Gamma \\
\hline Systemic & & $990\left(500-2,200^{\mathrm{a}}\right)$ & {$[40]$} & $\left.2,182\left(900-3,000^{\mathrm{a}}\right)\right)$ & [39] & Gamma \\
\hline Myocardic & & $5,021\left(1,800-8,000^{\mathrm{a}}\right)$ & {$[41]$} & $1,852\left(1,000-6,000^{\mathrm{a}}\right)$ & [39] & Gamma \\
\hline Intracranic & & $25,047\left(14,000-35,000^{a)}\right.$ & [42] & $14,531(10,000-30,000)$ & [37] & Gamma \\
\hline Extracrani & & $13,690\left(2,000-20,000^{\mathrm{a}}\right)$ & {$[43]$} & $2,256\left(1,500-15,000^{\mathrm{a}}\right)$ & [39] & Gamma \\
\hline Disability & & $480\left(200-800^{\mathrm{a}}\right)$ & [36] & $780\left(400-1,000^{\mathrm{a}}\right)$ & {$[37]$} & Gamma \\
\hline \multicolumn{7}{|c|}{ Discount rate (yearly, \%) } \\
\hline Costs & & $4\left(0-8^{a}\right)$ & [34] & $3.5\left(0-6^{\mathrm{a}}\right)$ & {$[33]$} & - \\
\hline Effects & & $1.5\left(0-3^{\mathrm{a}}\right)$ & [34] & $3.5\left(0-6^{\mathrm{a}}\right)$ & {$[33]$} & - \\
\hline \multicolumn{7}{|c|}{ a Assumption } \\
\hline \multicolumn{7}{|c|}{ b Own data and [12] } \\
\hline \multicolumn{7}{|c|}{ c Range in Dutch clinics } \\
\hline \multicolumn{7}{|c|}{$\mathrm{d} \pm 20 \%$} \\
\hline \multicolumn{7}{|c|}{ e After stroke or intracranial hemorrhage } \\
\hline$I N R$ intern & ed $\mathrm{r}$ & & & & & \\
\hline
\end{tabular}


Fig. 2 First-year incidence of clinical events per 100 patientyears. $E C H$ extra cranial hemorrhage, $\mathrm{ICH}$ intracranial hemorrhage, IS ischaemic stroke, MI myocardial infarction, $S E$ systemic embolism, TIA transient ischaemic attack

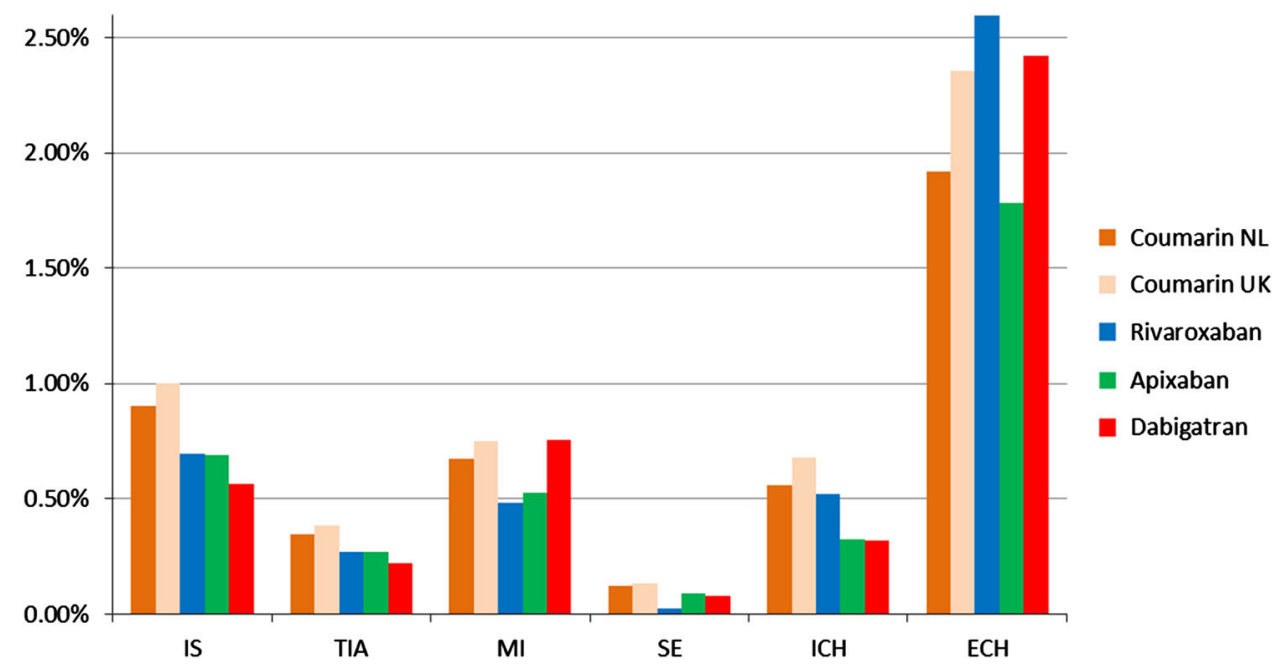

a wider range, to take into account the potentially large differences in costs between the two countries. Second, we performed a probabilistic sensitivity analysis using 10,000 Monte Carlo simulations to evaluate the combined impact of multiple model parameters on the estimated cost effectiveness of the new oral anticoagulants. Dirichlet distributions were used to vary the probabilities of different outcomes of stroke and ICH (more than two possible results). Beta distributions were used for all other probabilities and QALYs, and gamma distributions for the costs. A normal distribution was used to vary the frequency of INR measurements, the age of the patients and the percentage time spent in the therapeutic INR range. A scatter plot will be made depicting the incremental costs and effects of every simulation.

In the UK, NICE expressed a willingness-to-pay threshold of $£ 20,000-30,000$ per QALY gained [44]. The Dutch guidelines do not express such a threshold because it depends on different factors, but $€ 20,000$ was often used in previous reimbursement decisions [45]. We therefore studied the chance that the new oral anticoagulants would be cost effective at thresholds of $€ 20,000$ (Dutch threshold, approximately $£ 16,317$ ) and $€ 36,000$ (UK upper threshold, approximately $£ 30,000$ ), but also varied this threshold over a wider range in a cost-effectiveness acceptability curve. The costeffectiveness acceptability curve displays the chance that a particular intervention is the optimal intervention (i.e., most cost-effective one) at various willingness-to-pay thresholds.

\section{Results}

\subsection{Base Case}

Figure 2 shows the first-year incidence of the clinical events per 100 patient-years for coumarin derivatives in the
Netherlands, coumarin derivatives in the UK, and apixaban, rivaroxaban, or dabigatran in both countries. All three new oral anticoagulants had a lower stroke rate than the coumarin derivatives. ECHs were more frequent in rivaroxaban and dabigatran, but less frequent in apixaban than in either of the coumarins.

Table 3 shows the results of the cost-effectiveness analyses of the new oral anticoagulants compared with a coumarin derivative in the Netherlands and the UK. In the Netherlands, rivaroxaban use increased costs by $€ 5,681$, apixaban use by $€ 4,754$, and dabigatran use by $€ 5,465$ compared with the coumarin derivative. QALYs were increased by $0.166,0.365$, and 0.374 , respectively. The ICER compared with the coumarin derivative was $€ 34,248$ per QALY gained for rivaroxaban, $€ 13,024$ per QALY gained for apixaban, and $€ 14,626$ per QALY gained for dabigatran. When all options were taken into account, rivaroxaban was dominated by apixaban and dabigatran (higher costs, lower QALYs). The ICER of dabigatran versus apixaban was €82,292 per QALY gained.

In the UK, the incremental costs compared with coumarin derivatives were similar for all three new oral anticoagulants (€5,118-5,217). Rivaroxaban use increased QALYs by 0.302 , apixaban by 0.455 , and dabigatran by 0.461 . The ICERs of apixaban ( $€ 11,470$ per QALY gained) and dabigatran ( $€ 11,171$ per QALY gained) were somewhat lower than that of rivaroxaban $(€ 16,949$ per QALY gained). When all options were taken into account, rivaroxaban (higher ICER, lower QALYs) and apixaban (higher costs, lower QALYs) were dominated by dabigatran.

The costs per life-year gained of rivaroxaban, apixaban, and dabigatran were $€ 58,835, € 14,117$, and $€ 15,860$, respectively, in the Netherlands and $€ 18,420, € 11,300$, and $€ 11,029$ in the UK. 
Table 3 Results of the cost-effectiveness analysis: base case

\begin{tabular}{|c|c|c|c|c|c|}
\hline Treatment & Total costs $(€)$ & $\begin{array}{l}\text { Total } \\
\text { QALYs }\end{array}$ & $\Delta$ costs $(€)$ & $\Delta$ QALYs & ICER (€/QALY gained) \\
\hline \multicolumn{6}{|l|}{ The Netherlands } \\
\hline $\begin{array}{l}\text { Coumarin } \\
\text { derivative }\end{array}$ & $\begin{array}{l}8,829 \\
\quad(12,411)\end{array}$ & $\begin{array}{l}9.625 \\
\quad(11.026)\end{array}$ & Not applicable & & \\
\hline Rivaroxaban & $\begin{array}{l}14,510 \\
(20,443)\end{array}$ & $\begin{array}{l}9.791 \\
\quad(11.223)\end{array}$ & $\begin{array}{l}5,681(8,033)^{\mathrm{a}} / \\
\text { dominated }\end{array}$ & $0.166(0.197)^{\mathrm{a}} /$ dominated & $34,248(40,805)^{\mathrm{a}} /$ dominated \\
\hline Apixaban & $\begin{array}{l}13,583 \\
(19,217)\end{array}$ & $\begin{array}{l}9.990 \\
(11.471)\end{array}$ & $4,754(6,807)^{\mathrm{a}}$ & $0.365(0.444)^{\mathrm{a}}$ & $13,024(15,315)^{\mathrm{a}}$ \\
\hline Dabigatran & $\begin{array}{l}14,294 \\
(22,225)\end{array}$ & $\begin{array}{l}9.999 \\
(11.482)\end{array}$ & $\begin{array}{l}5,465(7,814)^{\mathrm{a}} / 711 \\
(1,008)^{\mathrm{b}}\end{array}$ & $\begin{array}{l}0.374(0.456)^{\mathrm{a}} / 0.009 \\
(0.011)^{\mathrm{b}}\end{array}$ & $\begin{array}{l}14,626(17,151)^{\mathrm{a}} / 82,292 \\
(90,241)^{\mathrm{b}}\end{array}$ \\
\hline \multicolumn{6}{|l|}{ The UK } \\
\hline $\begin{array}{l}\text { Coumarin } \\
\text { derivative }\end{array}$ & $\begin{array}{l}7,775 \\
(10,504)\end{array}$ & $\begin{array}{l}7.966 \\
(10.763)\end{array}$ & Not applicable & & \\
\hline Rivaroxaban & $\begin{array}{l}12,893 \\
(17,549)\end{array}$ & $\begin{array}{l}8.268 \\
(11.237)\end{array}$ & $\begin{array}{l}5,118(7,044)^{\mathrm{a}} / \\
\text { dominated }\end{array}$ & $0.302(0.473)^{\mathrm{a}} /$ dominated & $16,949(14,882)^{\mathrm{a}} /$ dominated \\
\hline Apixaban & $\begin{array}{l}12,992 \\
(17,749)\end{array}$ & $\begin{array}{l}8.421 \\
\quad(11.489)\end{array}$ & $\begin{array}{l}5,217(7,245)^{\mathrm{a}} / \\
\text { dominated }\end{array}$ & $0.455(0.726)^{\mathrm{a}} /$ dominated & $11,470(9,984)^{\mathrm{a}} /$ dominated \\
\hline Dabigatran & $\begin{array}{l}12,927 \\
(17,660)\end{array}$ & $\begin{array}{l}8.427 \\
(11.500)\end{array}$ & $5,152(7,156)^{\mathrm{a}}$ & $0.461(0.737)^{\mathrm{a}}$ & $11,172(9,709)^{\mathrm{a}}$ \\
\hline
\end{tabular}

Results using the country-specific discount rates are shown. Figures in parentheses indicate non-discounted results

${ }^{\text {a }}$ Compared with coumarin derivative

b Compared with apixaban

ICER incremental cost-effectiveness ratio, $Q A L Y$ quality-adjusted life-year

\subsection{Sensitivity Analyses}

Figures S1 to S6 in the ESM show the tornado diagrams summarizing the results of the one-way sensitivity analysis. These diagrams depict the influence of key parameters on the ICER. In the Netherlands, the percentage time in range (varied from 63 to $89 \%$ ) had the largest impact on the cost-effectiveness results for all three new oral anticoagulants. This parameter had a smaller impact in the UK (varied from 50 to $76 \%$ ) where for rivaroxaban the probability of ICH (varied from 0.33 to 0.85 ) had the largest impact on the cost-effectiveness results. The costs of adverse events did not have a large influence on the ICER in any of the comparisons, even though these were varied over a wide range.

In the probabilistic sensitivity analysis, the new oral anticoagulants were more costly and more effective than coumarins in the majority of the simulations (Fig. 3). The mean costs and effects from the simulations were similar to our point estimate from the deterministic analysis. Figure 4 shows the probability that any of the different oral anticoagulants would be the most cost-effective option in the Netherlands or in the UK over a range of likely willingness-to-pay thresholds. In the Netherlands, apixaban had the highest chance to be the most cost-effective option at a willingness-to-pay threshold of $€ 20,000$ or $€ 36,000$ per QALY gained (37 and $42 \%$, respectively). The ICER was below these thresholds in 28 and $38 \%$ of the simulations for dabigatran and in 2 and $2 \%$ of the simulations for rivaroxaban, respectively. In the UK, dabigatran had the highest chance to be the most cost-effective option at a willingness-to-pay threshold of $€ 20,000$ or $€ 36,000$ per QALY gained (41 and $48 \%$, respectively). These chances were lower for apixaban (35 and $41 \%$, respectively) and rivaroxaban (5 and $4 \%$, respectively).

\section{Discussion}

Our results confirm that apixaban, rivaroxaban, and dabigatran are all cost-effective alternatives to warfarin in the UK. However, in the Netherlands, the incremental costs per QALY gained for these new oral anticoagulants are higher and rivaroxaban could not be considered cost effective at a willingness-to-pay threshold of $€ 20,000$ per QALY gained. The percentage time spent in the therapeutic INR range had an important effect on the cost-effectiveness ratio. These results indicate that the cost effectiveness of the new oral anticoagulants is largely dependent on the setting and quality of local anticoagulant care facilities. 
Fig. 3 Scatter plots reflecting the uncertainty in the differences in costs and effectiveness between the new oral anticoagulants and coumarins (based on probabilistic sensitivity analysis). $Q A L Y$ qualityadjusted life-year
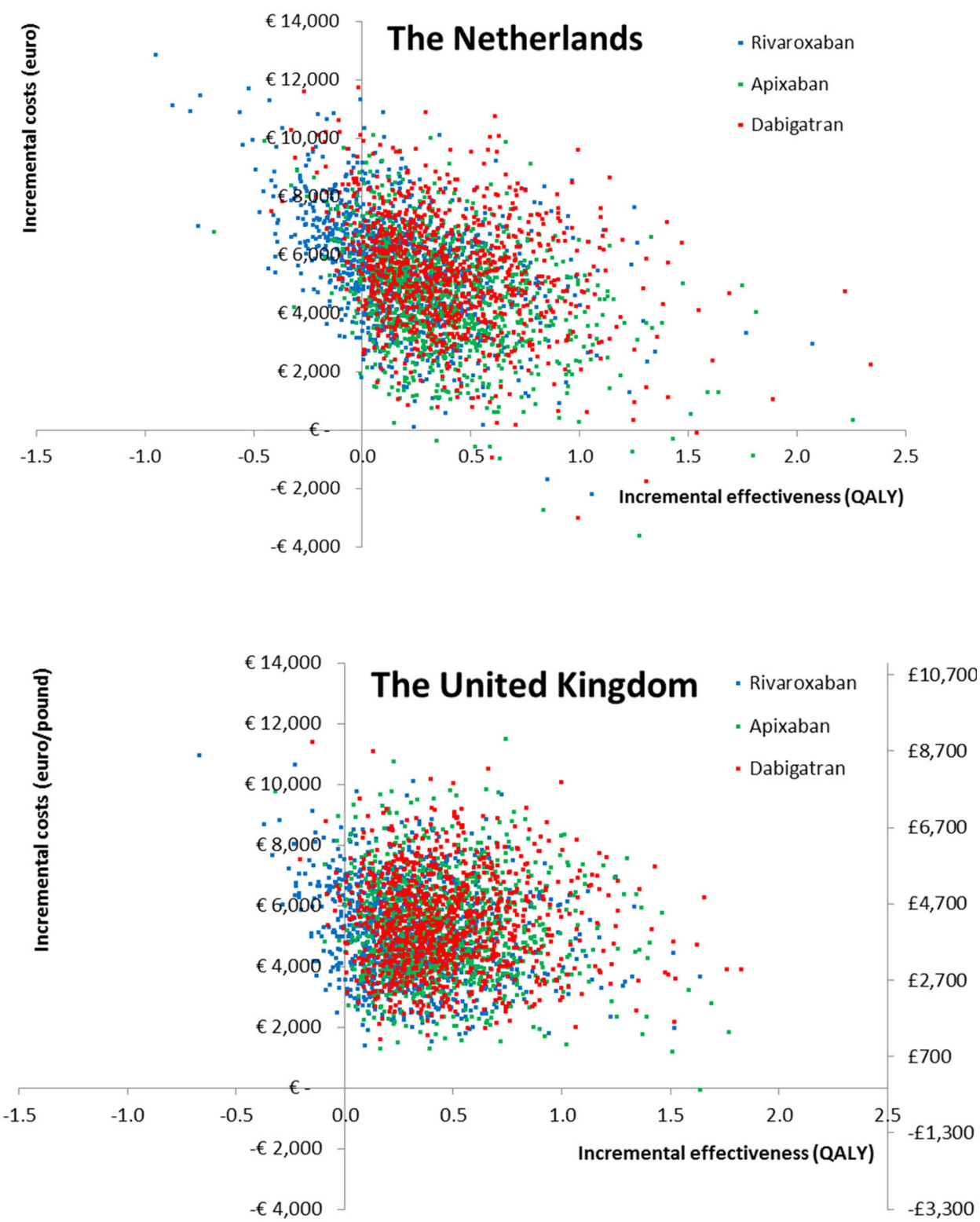

To our knowledge, this is the first study comparing the cost effectiveness of the new oral anticoagulants in two different countries with different healthcare settings. Moreover, the cost effectiveness of these new drugs in the Dutch setting has not been published before. For the UK, Pink et al. [46] showed a base-case ICER for dabigatran of $£ 23,082$ (approximately $€ 28,000$ ) and a $60 \%$ chance that this drug would be cost effective at a threshold of $£ 30,000$. Alternatively, the base-case ICER in a study by Kansal et al. [47] was $£ 4,831$ (approximately $€ 5,900$ ), and in a study by Faria et al. [48] $£ 7,940$ (approximately $€ 10,000)$. This difference is probably caused by differences in cost and quality-of-life estimates. For example, higher long-term costs of stroke and higher warfarin monitoring costs were used in the study by Kansal et al.
[47] In our study, the ICER of dabigatran in the UK was somewhere in between, at $€ 11,400$ per QALY gained. In another study in the UK, the ICER of apixaban versus warfarin was $£ 11,909$ (approximately $€ 15,000$ ) [49], which compares to the ICER of $€ 11,655$ in our study. Recently, a few studies investigating the cost effectiveness of the three new oral anticoagulants together have been published. These have focused on several different countries, including the USA [50-52], Germany [53], France [54], Italy [55], Norway [56], and the UK [57]. Overall, apixaban had the highest chance of being cost effective, while rivaroxaban had the lowest chance. In the UK study, new oral anticoagulants were compared with standard warfarin treatment as well as pharmacogeneticguided warfarin treatment [57]. Apixaban remained the 
Fig. 4 Cost-effectiveness Netherlands and the UK. QALY quality-adjusted life-year acceptability curve for the

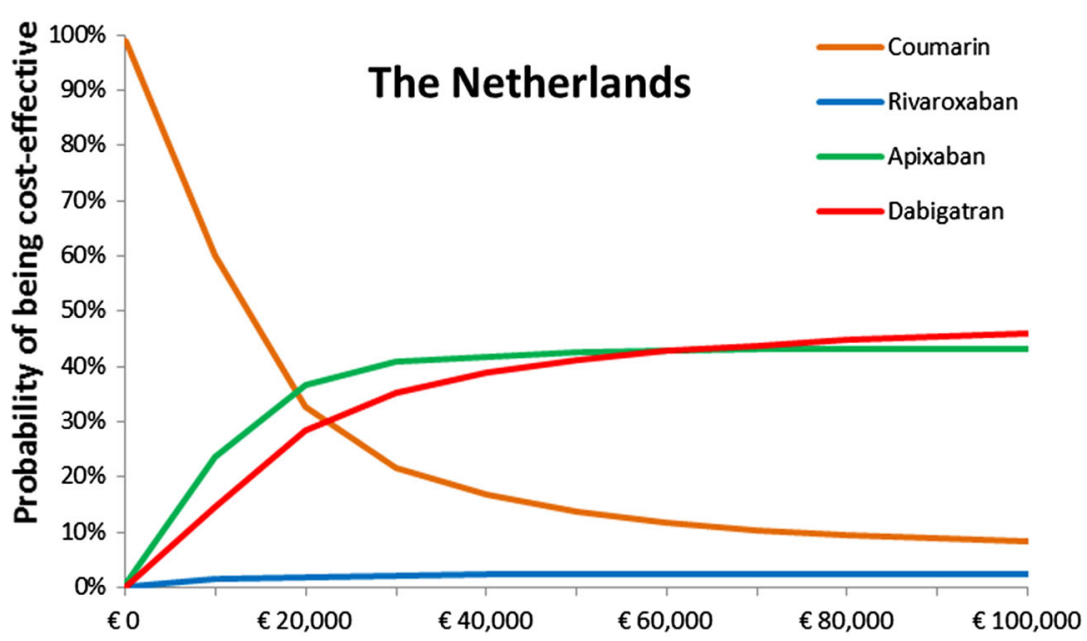

Willingness-to-pay (€ per QALY gained)

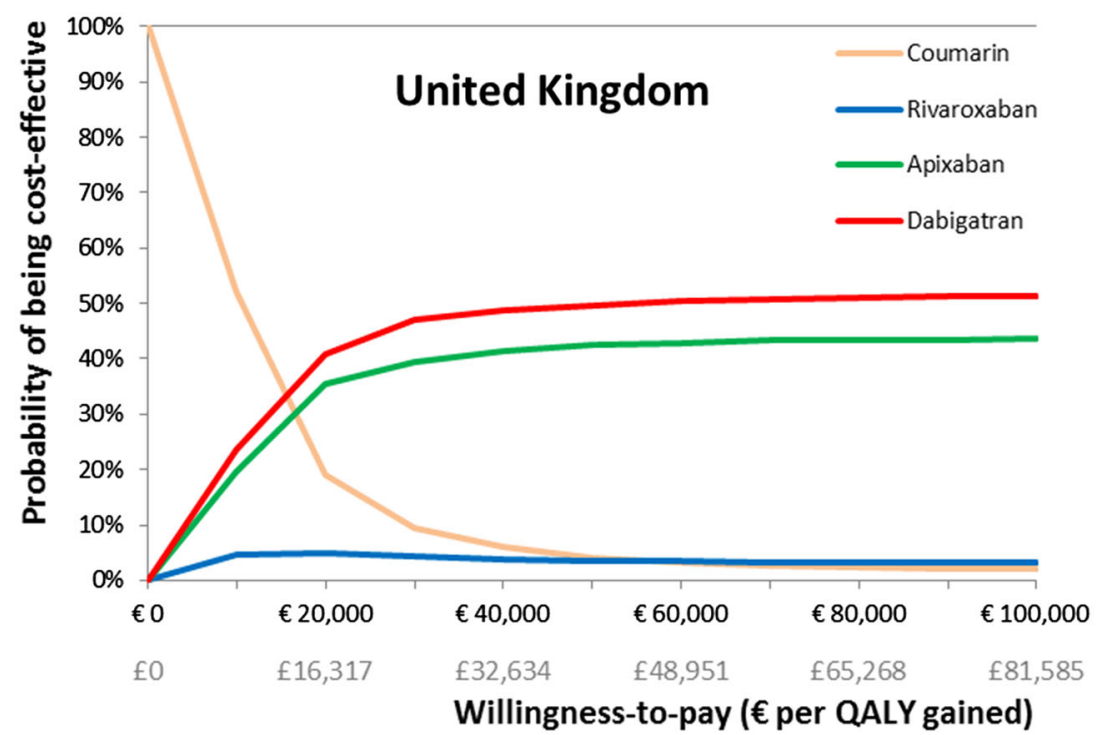

most cost-effective option if compared with both warfarin strategies.

Although we adjusted the clinical event rates from the three trials for differences in baseline risks, uncertainty remains about the comparison between the three different new oral anticoagulants. Because the three drugs have not been studied in a head-to-head trial, it was not possible to investigate the cost effectiveness of these drugs using information from a direct comparison. Another limitation is that the follow-up in the three trials was approximately 2 years. We extrapolated these data to a lifetime horizon, assuming the event rates would remain stable after 2 years. Lastly, because no official cost-effectiveness threshold exists in the Netherlands, it is difficult to state whether or not a new therapy will be considered cost effective. This threshold is influenced by several factors, for example life expectancy or disease severity [45].
In this study, we used a healthcare sector perspective, while the Dutch guidelines recommend using a societal perspective. This will not have a large influence on the results because our study involves older patients and therefore no difference in productivity losses was expected. However, travel costs and time costs for the patients can differ between coumarin derivatives and the new oral anticoagulants because coumarin derivatives require frequent INR measurements while the new oral anticoagulants do not. We estimated that these costs could increase the costs of coumarin derivatives by approximately $€ 100$ per year. Addition of these costs does not alter the conclusions of our study, although it makes the use of coumarin derivatives somewhat less favorable.

Our results indicate that country- or healthcare settingspecific analyses are important to study the cost effectiveness of new oral anticoagulants compared with 
coumarin derivatives. Because of differences in costs of the drugs or differences in the treatment costs of clinical events, the cost effectiveness of drugs can differ between countries. But more important in this case is the difference in healthcare setting and quality of the treatment with coumarin derivatives. In the Dutch setting of anticoagulant clinics, with a high percentage time spent in the therapeutic INR range, the new drugs are less cost effective than in the English setting where patients are treated by the general practitioner and spend less time in the therapeutic INR range. The difference between the two countries is largely driven by the difference in INR control. In the sensitivity analysis, we show that if the percentage time in therapeutic INR range in the UK were higher, the ICER for the new anticoagulants would increase. However, as shown in the tornado diagrams, the ICER of dabigatran and apixaban in the UK would not reach the $£ 30,000$ threshold (approximately $€ 36,000)$ even if the percentage time in therapeutic range were as high as in the Netherlands (76 \%). The ICER for rivaroxaban would be just above $€ 40,000$ with a percentage time in therapeutic range as high as in the Netherlands. A strength of this study is that we compared the new oral anticoagulants with coumarin derivatives in two different countries using the same model and analyses, making the results easier to compare than the results from two different studies. In the UK, the USA, and several other countries, warfarin is the most frequently used coumarin derivative [58]. In the Netherlands, this drug is not registered and therefore acenocoumarol is the most frequently used coumarin derivative there. For this reason, we used data on warfarin to model the costs and effects of coumarin derivatives in the UK and data on acenocoumarol for the Netherlands. Because different coumarins were used in the two countries, the two comparisons are not identical, but based on clinical practice. We believe this would not cause differences in our results because of the similarity in mechanism and pharmacokinetic characteristics between the different coumarins [15] and because we adjusted for differences in percentage time in therapeutic range. However, a limitation in the comparison between the two countries is that the therapeutic INR range in the UK (and many other countries) is 2.0-3.0, while this range is 2.0-3.5 in the Netherlands. However, many differences between the countries are captured by looking at the differences in time spent in therapeutic INR range. As we combined this metric with the risks of events associated with different INR ranges, we were able to adjust for quality of coumarin anticoagulant care and could therefore use country-specific event rates.

Another limitation is the use of clinical trial data, instead of real-world data, to model the incidence of events with the new oral anticoagulants. The cost effectiveness of the new oral anticoagulants might be overestimated in this study, because we used data from the three large randomized trials, which might not represent the real-world population. Real-world data might better represent the population under study and, in this way, the cost effectiveness could be estimated more reliably. These data are not available yet and therefore we recommend that the cost effectiveness be re-assessed once the effectiveness of the new drugs can be studied with real-world data.

In the UK, apixaban, rivaroxaban, and dabigatran all appear to be cost-effective alternatives to warfarin, increasing health at acceptable costs. While all three new oral anticoagulants also lead to improved health in the Netherlands, the incremental costs of rivaroxaban are higher than what may be regarded as acceptable. In contrast, dabigatran and apixaban seem to be cost-effective options in the Netherlands. In both countries, the use of new oral anticoagulants will impact the healthcare budget. Also, the use of anticoagulation clinics might decrease when the new drugs are used more frequently. Whether it is better to spend the budget on new oral anticoagulants or on improving the quality of current care with coumarin derivatives (by for example pharmacogenetic-guided dosing) is an interesting question for debate.

Acknowledgments This Project is funded by the European Community's Seventh Framework Programme under grant agreement HEALTH-F2-2009-223062.

Open Access This article is distributed under the terms of the Creative Commons Attribution Noncommercial License which permits any noncommercial use, distribution, and reproduction in any medium, provided the original author(s) and the source are credited.

\section{References}

1. Hart RG, Pearce LA, Aguilar MI. Meta-analysis: antithrombotic therapy to prevent stroke in patients who have nonvalvular atrial fibrillation. Ann Intern Med. 2007;146(12):857-67.

2. Ansell J, Hirsh J, Hylek E, Jacobson A, Crowther M, Palareti G. Pharmacology and management of the vitamin $\mathrm{K}$ antagonists: American College of Chest Physicians Evidence-Based Clinical Practice Guidelines (8th Edition). Chest. 2008;133(6 Suppl):160s-98s. doi:10.1378/chest.08-0670.

3. Connolly SJ, Ezekowitz MD, Yusuf S, Eikelboom J, Oldgren J, Parekh A, et al. Dabigatran versus warfarin in patients with atrial fibrillation. N Eng J Med. 2009;361(12):1139-51. doi:10.1056/ NEJMoa0905561.

4. Connolly SJ, Ezekowitz MD, Yusuf S, Reilly PA, Wallentin L. Newly identified events in the RE-LY trial. N Eng J Med. 2010;363(19):1875-6. doi:10.1056/NEJMc1007378.

5. Granger CB, Alexander JH, McMurray JJ, Lopes RD, Hylek EM, Hanna $M$, et al. Apixaban versus warfarin in patients with atrial fibrillation. N Eng J Med. 2011;365(11):981-92. doi:10.1056/ NEJMoa1107039.

6. Patel MR, Mahaffey KW, Garg J, Pan G, Singer DE, Hacke W, et al. Rivaroxaban versus warfarin in nonvalvular atrial fibrillation. N Eng J Med. 2011;365(10):883-91. doi:10.1056/NEJM oa1009638. 
7. Miller CS, Grandi SM, Shimony A, Filion KB, Eisenberg MJ. Meta-analysis of efficacy and safety of new oral anticoagulants (dabigatran, rivaroxaban, apixaban) versus warfarin in patients with atrial fibrillation. Am J Cardiol. 2012;110(3):453-60. doi:10.1016/j.amjcard.2012.03.049.

8. Holster IL, Valkhoff VE, Kuipers EJ, Tjwa ET. New oral anticoagulants increase risk for gastrointestinal bleeding: a systematic review and meta-analysis. Gastroenterology. 2013;145(1): 105-12.e15. doi:10.1053/j.gastro.2013.02.041.

9. Kansal AR, Zheng Y, Pokora T, Sorensen SV. Cost-effectiveness of new oral anticoagulants in the prevention of stroke in patients with atrial fibrillation. Best Pract Res Clin Haematol. 2013;26(2):225-37. doi:10.1016/j.beha.2013.07.012.

10. Limone BL, Baker WL, Kluger J, Coleman CI. Novel anticoagulants for stroke prevention in atrial fibrillation: a systematic review of cost-effectiveness models. PloS One. 2013;8(4):e621 83. doi:10.1371/journal.pone.0062183.

11. Verhoef TI, Redekop WK, van Schie RM, Bayat S, Daly AK, Geitona $\mathrm{M}$, et al. Cost-effectiveness of pharmacogenetics in anticoagulation: international differences in healthcare systems and costs. Pharmacogenomics. 2012;13(12):1405-17. doi:10. 2217/pgs.12.124.

12. Federation of Dutch Anticoagulant clinics. Samenvatting medische jaarverslagen 2011. http://www.fnt.nl/media/docs/jaarverslagen/ Medisch_Jaarverslag_FNT_2011.pdf. Accessed 11 Aug 2014.

13. Connock M, Stevens C, Fry-Smith A, Jowett S, Fitzmaurice D, Moore D, et al. Clinical effectiveness and cost-effectiveness of different models of managing long-term oral anticoagulation therapy: a systematic review and economic modelling. Health Technol Assess (Winch Eng). 2007;11(38):3-4 (9-66).

14. Gallagher AM, Setakis E, Plumb JM, Clemens A, van Staa TP. Risks of stroke and mortality associated with suboptimal anticoagulation in atrial fibrillation patients. Thromb Haemost. 2011;106(5):968-77. doi:10.1160/th11-05-0353.

15. Schalekamp T, de Boer A. Pharmacogenetics of oral anticoagulant therapy. Curr Pharm Design. 2010;16(2):187-203.

16. Fang MC, Go AS, Chang Y, Hylek EM, Henault LE, Jensvold $\mathrm{NG}$, et al. Death and disability from warfarin-associated intracranial and extracranial hemorrhages. Am J Med. 2007;120(8): 700-5. doi:10.1016/j.amjmed.2006.07.034.

17. Bernheim SM, Grady JN, Lin Z, Wang Y, Wang Y, Savage SV, et al. National patterns of risk-standardized mortality and readmission for acute myocardial infarction and heart failure. Update on publicly reported outcomes measures based on the 2010 release. Circ Cardiovasc Qual Outcomes. 2010;3(5):459-67. doi:10.1161/circoutcomes.110.957613.

18. Krumholz HM, Merrill AR, Schone EM, Schreiner GC, Chen J, Bradley EH, et al. Patterns of hospital performance in acute myocardial infarction and heart failure 30-day mortality and readmission. Circ Cardiovasc Qual Outcomes. 2009;2(5):407-13. doi:10.1161/circoutcomes.109.883256.

19. Meckley LM, Gudgeon JM, Anderson JL, Williams MS, Veenstra DL. A policy model to evaluate the benefits, risks and costs of warfarin pharmacogenomic testing. Pharmacoeconomics. 2010;28(1):61-74. doi:10.2165/11318240-000000000-00000.

20. Centraal bureau voor de statistiek, life tables. http://statline.cbs. nl/statweb/. Accessed 11 Aug 2014.

21. Office of National Statistics, life tables. http://www.statistics.gov. uk/. Accessed 11 Aug 2014.

22. World Health Organization, Global Health Observatory Data Repository. http://apps.who.int/gho/data/?vid=710\#.

23. Bucher HC, Guyatt GH, Griffith LE, Walter SD. The results of direct and indirect treatment comparisons in meta-analysis of randomized controlled trials. J Clin Epidemiol. 1997;50(6): 683-91.
24. Oake N, Jennings A, Forster AJ, Fergusson D, Doucette S, van Walraven C. Anticoagulation intensity and outcomes among patients prescribed oral anticoagulant therapy: a systematic review and meta-analysis. CMAJ. 2008;179(3):235-44. doi:10. 1503/cmaj.080171.

25. O'Brien CL, Gage BF. Costs and effectiveness of ximelagatran for stroke prophylaxis in chronic atrial fibrillation. JAMA. 2005;293(6):699-706. doi:10.1001/jama.293.6.699.

26. Shah SV, Gage BF. Cost-effectiveness of dabigatran for stroke prophylaxis in atrial fibrillation. Circulation. 2011;123(22): 2562-70. doi:10.1161/circulationaha.110.985655.

27. Verhoef TI, Redekop WK, Buikema MM, Schalekamp T, Van Der Meer FJ, Le Cessie S, et al. Long-term anticoagulant effects of the CYP2C9 and VKORC1 genotypes in acenocoumarol users. J Thromb Haemost. 2012;10(4):606-14. doi:10.1111/j.15387836.2012.04633.x.

28. Sullivan PW, Arant TW, Ellis SL, Ulrich H. The cost effectiveness of anticoagulation management services for patients with atrial fibrillation and at high risk of stroke in the US. Pharmacoeconomics. 2006;24(10):1021-33.

29. Jowett S, Bryan S, Mahe I, Brieger D, Carlsson J, Kartman B, et al. A multinational investigation of time and traveling costs in attending anticoagulation clinics. Value Health. 2008;11(2): 207-12. doi:10.1111/j.1524-4733.2007.00253.x.

30. Dutch healthcare authority. Beleidsregel voor trombosediensten. http://www.nza.nl/137706/145406/623721/BR-CU-2083-Trombosediensten.pdf. Accessed 15 May 2014.

31. National Institute of Health and Clinical Excellence. Apixaban for preventing stroke and systemic embolism in people with nonvalvular atrial fibrillation. NICE technology appraisal guidance 275. 2013. http://www.nice.org.uk/nicemedia/live/14086/ 62874/62874.pdf. Accessed 15 May 2014.

32. Dutch drug costs. Available from: http://www.medicijnkosten.nl.

33. International society for pharmacoeconomics and outcomes research.

34. Hakkaart-van Roijen L, Tan SS, Bouwmans CAM. Handleiding voor kostenonderzoek. Methoden en standaard kostprijzen voor economische evaluaties in de gezondheidszorg. Instituut voor Medical Technology Assessment, Erasmus Universiteit Rotterdam, in opdracht van het College voor Zorgverzekeringen. 2010.

35. National Institute of Health and Clinical Excellence. Dabigatran etexilate for the prevention of stroke and systemic embolism in atrial fibrillation. Final appraisal determination. 2011. http://www. nice.org.uk/nicemedia/live/12225/56899/56899.pdf. Accessed 15 May 2014.

36. Struijs JN, van Genugten ML, Evers SM, Ament AJ, Baan CA, van den Bos GA. Future costs of stroke in The Netherlands: the impact of stroke services. Int $\mathrm{J}$ Technol Assess Health Care. 2006;22(4):518-24. doi:10.1017/s0266462306051464.

37. Luengo-Fernandez R, Yiin GS, Gray AM, Rothwell PM. Population-based study of acute- and long-term care costs after stroke in patients with AF. Int J Stroke. 2013;8(5):308-14. doi:10.1111/ j.1747-4949.2012.00812.x.

38. Buisman LR, Tan SS, Koudstaal PJ, Nederkoorn PJ, Redekop WK. Hospital costs of ischemic stroke and transient ischemic attack in The Netherlands. ISPOR 17th Annual European Congress to be held 8-12 November 2014 at the Amsterdam RAI, Amsterdam, The Netherlands.

39. Department of Health. NHS Trusts and PCTs combined reference cost schedules 2010-11. http://www.dh.gov.uk/prod_consum_dh/ groups/dh_digitalassets/documents/digitalasset/dh_131148.xls. Accessed 15 May 2014.

40. Dutch healthcare authority. NZa. DBC-tariefapplicatie. 2011. http://dbc-tarieven.nza.nl/Nzatarieven/top.do.

41. Greving JP, Visseren FL, de Wit GA, Algra A. Statin treatment for primary prevention of vascular disease: whom to treat? Cost- 
effectiveness analysis. BMJ (Clin Res Ed). 2011;342:d1672. doi:10.1136/bmj.d1672.

42. Roos YB, Dijkgraaf MG, Albrecht KW, Beenen LF, Groen RJ, de Haan RJ, et al. Direct costs of modern treatment of aneurysmal subarachnoid hemorrhage in the first year after diagnosis. Stroke J Cereb Circ. 2002;33(6):1595-9.

43. Schalekamp T, Boink GJ, Visser LE, Stricker BH, de Boer A, Klungel $\mathrm{OH}$. CYP2C9 genotyping in acenocoumarol treatment: is it a cost-effective addition to international normalized ratio monitoring? Clin Pharmacol Ther. 2006;79(6):511-20. doi:10. 1016/j.clpt.2006.03.008.

44. Devlin N, Parkin D. Does NICE have a cost-effectiveness threshold and what other factors influence its decisions? A binary choice analysis. Health Econ. 2004;13(5):437-52. doi:10.1002/ hec. 864 .

45. Stolk EA, van Donselaar G, Brouwer WB, Busschbach JJ. Reconciliation of economic concerns and health policy: illustration of an equity adjustment procedure using proportional shortfall. Pharmacoeconomics. 2004;22(17):1097-107.

46. Pink J, Lane S, Pirmohamed M, Hughes DA. Dabigatran etexilate versus warfarin in management of non-valvular atrial fibrillation in UK context: quantitative benefit-harm and economic analyses. BMJ (Clin Res Ed). 2011;343:d6333. doi:10.1136/bmj.d6333.

47. Kansal AR, Sorensen SV, Gani R, Robinson P, Pan F, Plumb JM, et al. Cost-effectiveness of dabigatran etexilate for the prevention of stroke and systemic embolism in UK patients with atrial fibrillation. Heart. 2012;98(7):573-8. doi:10.1136/heartjnl-2011300646.

48. Faria R, Spackman E, Burch J, Corbacho B, Todd D, Pepper C, et al. Dabigatran for the prevention of stroke and systemic embolism in atrial fibrillation: a NICE single technology appraisal. Pharmacoeconomics. 2013;31(7):551-62. doi:10.1007/ s40273-013-0051-8.

49. Dorian P, Kongnakorn T, Phatak H, Rublee DA, Kuznik A, Lanitis $\mathrm{T}$ et al. Cost-effectiveness of apixaban vs. current standard of care for stroke prevention in patients with atrial fibrillation. Eur Heart J. 2014;35(28):1897-906. doi:10.1093/eurheartj/ ehu006.

50. Canestaro WJ, Patrick AR, Avorn J, Ito K, Matlin OS, Brennan TA, et al. Cost-effectiveness of oral anticoagulants for treatment of atrial fibrillation. Circ Cardiovasc Qual Outcomes. 2013;6(6):724-31. doi:10.1161/circoutcomes.113.000661.

51. Coyle D, Coyle K, Cameron C, Lee K, Kelly S, Steiner S, et al. Cost-effectiveness of new oral anticoagulants compared with warfarin in preventing stroke and other cardiovascular events in patients with atrial fibrillation. Value Health. 2013;16(4): 498-506. doi:10.1016/j.jval.2013.01.009.

52. Harrington AR, Armstrong EP, Nolan PE Jr, Malone DC. Costeffectiveness of apixaban, dabigatran, rivaroxaban, and warfarin for stroke prevention in atrial fibrillation. Stroke J Cereb Circ. 2013;44(6):1676-81. doi:10.1161/strokeaha.111.000402.

53. Krejczy M, Harenberg J, Marx S, Obermann K, Frolich L, Wehling M. Comparison of cost-effectiveness of anticoagulation with dabigatran, rivaroxaban and apixaban in patients with nonvalvular atrial fibrillation across countries. J Thromb Thrombolysis. 2014;37(4):507-23. doi:10.1007/s11239-013-0989-6.

54. Lanitis T, Cotte FE, Gaudin AF, Kachaner I, Kongnakorn T, Durand-Zaleski I. Stroke prevention in patients with atrial fibrillation in France: comparative cost-effectiveness of new oral anticoagulants (apixaban, dabigatran, and rivaroxaban), warfarin, and aspirin. J Med Econ. 2014;17(8):587-98. doi:10.3111/ 13696998.2014.923891.

55. Rognoni C, Marchetti M, Quaglini S, Liberato NL. Apixaban, dabigatran, and rivaroxaban versus warfarin for stroke prevention in non-valvular atrial fibrillation: a cost-effectiveness analysis. Clin Drug Investig. 2014;34(1):9-17. doi:10.1007/s40261-0130144-3.

56. Wisloff T, Hagen G, Klemp M. Economic evaluation of warfarin, dabigatran, rivaroxaban, and apixaban for stroke prevention in atrial fibrillation. Pharmacoeconomics. 2014;32(6):601-12. doi:10.1007/s40273-014-0152-z.

57. Pink J, Pirmohamed M, Lane S, Hughes DA. Cost-effectiveness of pharmacogenetics-guided warfarin therapy vs. alternative anticoagulation in atrial fibrillation. Clin Pharmacol Ther. 2014;95(2):199-207. doi:10.1038/clpt.2013.190.

58. Pengo V, Pegoraro C, Cucchini U, Iliceto S. Worldwide management of oral anticoagulant therapy: the ISAM study. J Thromb Thrombolysis. 2006;21(1):73-7. doi:10.1007/s11239-006-5580-y. 